\title{
High-dose Methylprednisolone Regimen
}

National Cancer Institute

\section{Source}

National Cancer Institute. High-dose Methylprednisolone Regimen. NCI Thesaurus. Code C160805.

A regimen consisting of high-dose methylprednisolone sodium succinate that may be used in the palliative management of acute lymphoblastic leukemia (ALL); and in the management of severe allergic conditions, hypercalcemia of malignancy, idiopathic thrombocytopenic purpura (ITP), Crohn's disease, and other inflammatory disorders. 